\title{
Decision Support System for RichDess Poultry and Egg Farm
}

\author{
Michelle Renee Ching ${ }^{1}$, Shaun Cassidy Calagos ${ }^{1}$, Katrina Michaela Delfin ${ }^{1+}$, Carlos Miguel \\ Dignadice ${ }^{1}$, and Joshua Macuja ${ }^{1}$ \\ ${ }^{1}$ College of Computer Studies, De La Salle University, Philippines
}

\begin{abstract}
The most important enterprise in the world is Agriculture for it provides human's basic needs of survival. Because of the advancements in technology today, management of agricultural data and information related to the performance of livestock is vital for successful farms to compete in the market. This could be achieved through accurate Farm Management Information Systems that can provide decision support to achieve sustainability, optimum efficiency, and effectivity. Through Agile and Scrum development frameworks, the researchers specifically developed a Decision Support System for RichDess Poultry and Egg Farm that aids its farm employees in storing and utilizing data that would provide the necessary information to the farm manager in creating key business decisions. The system aims to maximize the assets and minimize the expenses of the farm through the four main modules: Poultry and Egg Management module, Pig Management module, Feeds and Medicine Inventory Tracking module, and Financial Management module. The system can suggest the best chicken breed to purchase based on each chicken breed's total egg production; moreover, it can suggest the type of medicine to cure certain illnesses based on past data. Additionally, it can monitor the weight and breeding status of the pigs. It can also display a clear picture of the farm's cash flow for easy decision-making and it can track the quantity of feeds and medicines used.
\end{abstract}

Keywords: livestock farming, Decision Support Systems, agriculture

\section{Introduction}

Agriculture helps to meet the human's basic needs for survival and their civilization by providing clothing, food, medicine, recreation, and shelters. Thus, agriculture can be considered the most important enterprise in the world. After a large increase in crop production in developing countries achieved using fertilizers, pesticides, and high-yield crop varieties known as the "Green Revolution" [1], farmers could enhance and maximize the production potential per unit land, time, and input by using improved cultural practices and agricultural inputs in intensive cropping systems along with labourer intensive programs. Management of agricultural data and information related to the performance of a livestock or cropping system is needed to have a successful operational farm [2]. To do this, accurate farm management is one of the most important success factors to achieve sustainable development and effectiveness in today's fast changing and competitive environment [3].

In today's world, accurate and easy to use Farm Management Information Systems (FMIS) are of fundamental importance for a successful operational farm. Despite the increasing usage of information technologies and professionalism in the agricultural sector, most farmers do not take advantage of these FMIS when it comes to operating their business [4]. Traditional farming methods hinder farmers and productivity of the farm from achieving their optimum efficiency and effectivity. FMIS offers a large variety of functions that can be suitable for all types of agricultural farms to help manage their farm in an effective and efficient manner.

\footnotetext{
+ Corresponding author.

E-mail address: kat.delfin13@gmail.com.
} 
The decisions of each farmer have impacts on sustainability and are made in a complex world of contradictious interests and values. Agricultural Decision Support Systems (AgriDSS) will be a major contributor in the realization of a viable farm economy [5]. It is important that farmers are able to make critical decisions to further improve their own processes in their farm to allow them to maximize their recourses and financial capabilities based on the farm's data and other internal or external variables. AgriDSS can help in making these crucial decisions in a timely matter with respect to the variables that need to be considered and provide farm owners with effective and easy to understand decisions.

The researchers aim to give importance on how technology, specifically information systems, can have a positive effect on production and productivity on agriculture while also providing effective financial decisions to further improve the processes of the farm and maximize profit by proposing a Decision Support System for RichDess Poultry and Egg Farm, a semi-commercial farm located in Mabalor, Ibaan, Batangas, Philippines. The farm's agricultural operations consist of poultry and egg production, and hog raising. The system will include functions to monitoring the performance of egg production per day, breeding performance and raising of pigs, and the finances of the farm by accurately tracking the expenses, income, and revenue.

\subsection{Background of the Study}

The Philippines is considered as one of the world's "mega biodiversity" countries, rich in both fauna and flora [6]. Abundant in natural resources, it is no surprise that the Philippines is a predominantly agricultural country. The agriculture sector is fundamental in food production and generating income through providing job opportunities and a source of livelihood for Filipino people. However, despite being blessed with the abundance of natural resources, agriculture contributes the least to the country's economic growth, also known as the Gross Domestic Product (GDP). The GDP is supported by three sectors of production: services, industry, and agriculture. From 1946 to 1969, agriculture accounted for 20\% to 30\% of GDP. Since 1970, the GDP share of agriculture has never gone beyond $20 \%$, according to government data [7]. Recently, agriculture's contribution to the economy has continued to dwindle, down to $11.06 \%$ of GDP in 2013.

The lack of GDP contribution by agriculture can be attributed to the lack of government support in agricultural development. Investments in human resource development, infrastructure and productivity should be made [7]. With this, the Philippine government are taking steps to further develop the agricultural sector. With the help of science, technology, and research and development, agriculture can be a lucrative industry that can foster food security in the Philippines [8]. Introducing innovative technologies would make farming more efficient and productive. Raising productivity using innovative technological solutions would support the economy, improve the quality of the products, gain more income, and provide opportunities for Filipino farmers. While established big commercial farms have computerized farm recording, medium to small scale farms mostly adopt manual recording. Most farmers could not interpret or analyze the data that they have listed to evaluate farm performance.

Globally, the poultry industry contributes to the world economy through providing a source of livelihood and protein for food in developing economies. In developed economies, the poultry industry enhances GDP profiles and provides high revenue from exports [9]. In 2013, among the major egg-producing regions in the world, Asia accounts for $40 \%$ of the world's egg production and has contributed 4,494 million out of 7,035 million of the total number of layers in the world [10]. This means that Asia is the most major region in terms of egg production globally. The Philippines comes in 11th place in Asia with 427.7 million in egg production [10]. To increase the rate of egg production in the country, the Department of Agriculture in the Philippines is taking steps in implementing rural infrastructure and technology build-up to develop and modernize the agricultural economy - including layer poultry farming and egg production [11]. To attain these goals, the Department, in partnership with Local Government Units (LGUs) and the private sector, would provide facilities and technology to farmers in support of improving production.

Furthermore, in the Swine Industry, more pork is eaten in the world than any other meat. Pork is the most consumed meat in the world (110 million metric tonnes, $\mathrm{mmt})$ - more than beef $(67 \mathrm{mmt})$ and chicken (104 mmt) [12]. Globally, the Philippine swine industry is ranked eighth in 2016 in terms of the volume of pork production and number of breeding sows (1,400 thousand metric tons) [13]. The Philippine swine 
industry plays a significant role in securing the nation's food security - accounting for about $60 \%$ of the total animal meat consumption of the Filipino people. The industry largely contributes to the nation's agriculture, and is placed second next to rice, for about $18.28 \%$ of the total value of agricultural production [14]. Twothirds of the total pigs in the Philippines is kept by small hold pig raisers [13]. The local pig industry is struggling with inefficiency of production attributable to low sow productivity, high mortality due to inefficient diagnostic tool, and lack of native pig genetic resource conservation, improvement and utilization initiative [14]. The government is taking steps to address these problems and ensure the growth of the hog industry. These efforts include the initiatives of the Philippine Council for Agriculture, Aquatic and Natural Resources Research and Development of the Department of Science and Technology (DOST-PCAARRD). Their program aims to address the current problems by developing technologies and systems that are expected to improve the productivity and production efficiency [14]. Part of their program was developing a web-based group monitoring system for pigs to improve farm productivity through better farm management and decision making. Using this monitoring system, data and images can be transmitted and viewed realtime using the desktop computer in the farm's office [14].

\subsection{Company Background}

RichDess Poultry and Egg Farm is a semi-commercial farm located in Mabalor, Ibaan, Batangas established in 2008 by Mr. Richard Humarang. Its processes comprise of poultry and egg production, and pig farming. For poultry and egg production, the farm currently has an estimate of 4,680 chickens in total. The farm has divided the chicken layer cages into three batches which consists of 1,560 chickens per batch. Each cage has the capacity to house 4 chickens. There is also a specific area that houses the batch of chickens that have sicknesses to avoid the risk of infecting the other healthy chickens. This area is called "The Hospital". "The Hospital" has the capacity to house 100 to 150 sick chickens. The sick chickens are given the appropriate medications until they are healthy again, which then they can return to their original batch. The farm's piggery has a capacity of 74 heads, but it currently only has 65 heads. This is comprised of 61 inahin (sows) and 4 barako (boars). Currently, there is no "Hospital" where the pigs with sicknesses can be separated to, but there is ongoing construction in the farm to create the facility and increase the total capacity of pigs.

\section{Objectives of the Study}

The researchers aim to solve the following problems present with the chosen farm company through the development of the DSS.

Inaccuracy in calculation of the egg production percentage

Ineffective design of the Egg Production Form

Difficulty analysing the farm's cash flow

No method of knowing which breed of chickens is good for producing quality eggs

Inaccurate date of sow farrowing

Profit is lost by feeding unproductive pigs

Loss of data

\section{Methodology}

The Agile Development was adopted in the system development because it is heavily client-centered. The researchers value the concept of clients having great understanding and control of the products that they are going to receive, as it often results in better customer satisfaction, effective development of the project, and a better product. Specifically, the Scrum framework was adopted because based on previous development experiences of the researchers, the framework was able to guide them in building the project more effectively since it requires the team to meet daily and to become transparent with the progress not just to the rest of the team but also to the client. It requires heavy communication among the stakeholders as it allows better cooperation within the team and better understanding of the project for the client. 
The development life cycle used in the project is different to the traditional SDLC (System Development Life Cycle) which usually consists of six phases: planning, analysis, design, build, test, and implement. This is because the methodology used comes in iterations, unlike the traditional development life cycle which comes in just one cycle. There are also six phases included in the methodology, these are: concept phase, iteration 0 , construction, release, production, and retirement.

\subsection{Concept Phase}

Also called Iteration -1 , this phase is when the client would conceptualize the potential projects that would increase business value, prioritize the potential projects based on the business value that the project will add to the company, and assess the feasibility of the projects by doing research and consulting experts regarding the project.

\subsection{Inception}

Also called Iteration 0, this phase and the previous phase are similar to the planning phase of the traditional development life cycle. In this phase, the researchers brainstormed about what requirements the system would have, how the system would look like, and what functionalities are to be included in the system. After modeling the iteration, the researchers set up their work environment to prepare for the first iteration to build the system.

\subsection{Construction}

The first iteration of development and the conducting of the rigorous test would occur on this phase. The iterations, also called as sprints, would follow the iteration model that was made in the previous phase, and the functionalities that were developed in this phase were the functionalities that were set during sprint modeling. Sprints usually last two to three weeks. Following the Scrum Development Framework, the scrum team which consists of two types (scrum members and scrum master) met daily at a specified place and time. During this phase, rigorous testing was done with every functionality being built. This is done to ensure that the functionality would work and not cause any problems during integration at the end of the sprint. After the sprint was done, the researchers demonstrated the finished product to the client and gathered feedback to be used in the next iteration. Afterwards, the researchers conducted a meeting to review their performance during the sprint and applied the corrections on the next iteration.

\subsection{Release}

During this phase, the system produced in the first sprint would go through final testing and acceptance training. The bugs found in the final testing were addressed by the researchers. The user documentation was also updated and finalized. After final testing and finalization of user documents, the researchers trained the end users of the system. When the system has enough business value and has reached its bare minimum requirements, it was deployed by the researchers to be used by the client. After which began the next iteration, implementation of updates, and finalization of the remaining functions in the product backlog until the final product has been achieved.

\subsection{Production}

The production phase is similar to the implementation phase of the traditional development life cycle. This phase usually needs its own sprint, because it applies to the operational lifetime of the system. This process will differ from organization to organization and perhaps even from system to system but the fundamental goal remains the same: keep the system running and help users use it [15].

\subsection{Retirement}

This phase is the end of the operational lifetime of the system. This phase occurs, when the system is being replaced, has become redundant (because of added processes), or has no longer supported the current business model. This typically occurs when there is a newer version of the existing system; though it is not necessary because some older systems are not retired for backwards compatibility.

\section{Results}


The researchers have developed a system that would aid the farm employees in storing and utilizing data that would provide the necessary information for creating key business decisions. It aims to maximize the assets and minimize the expenses of the farm, as shown in Figure 1. Each module is discussed in detail in the succeeding subsections.

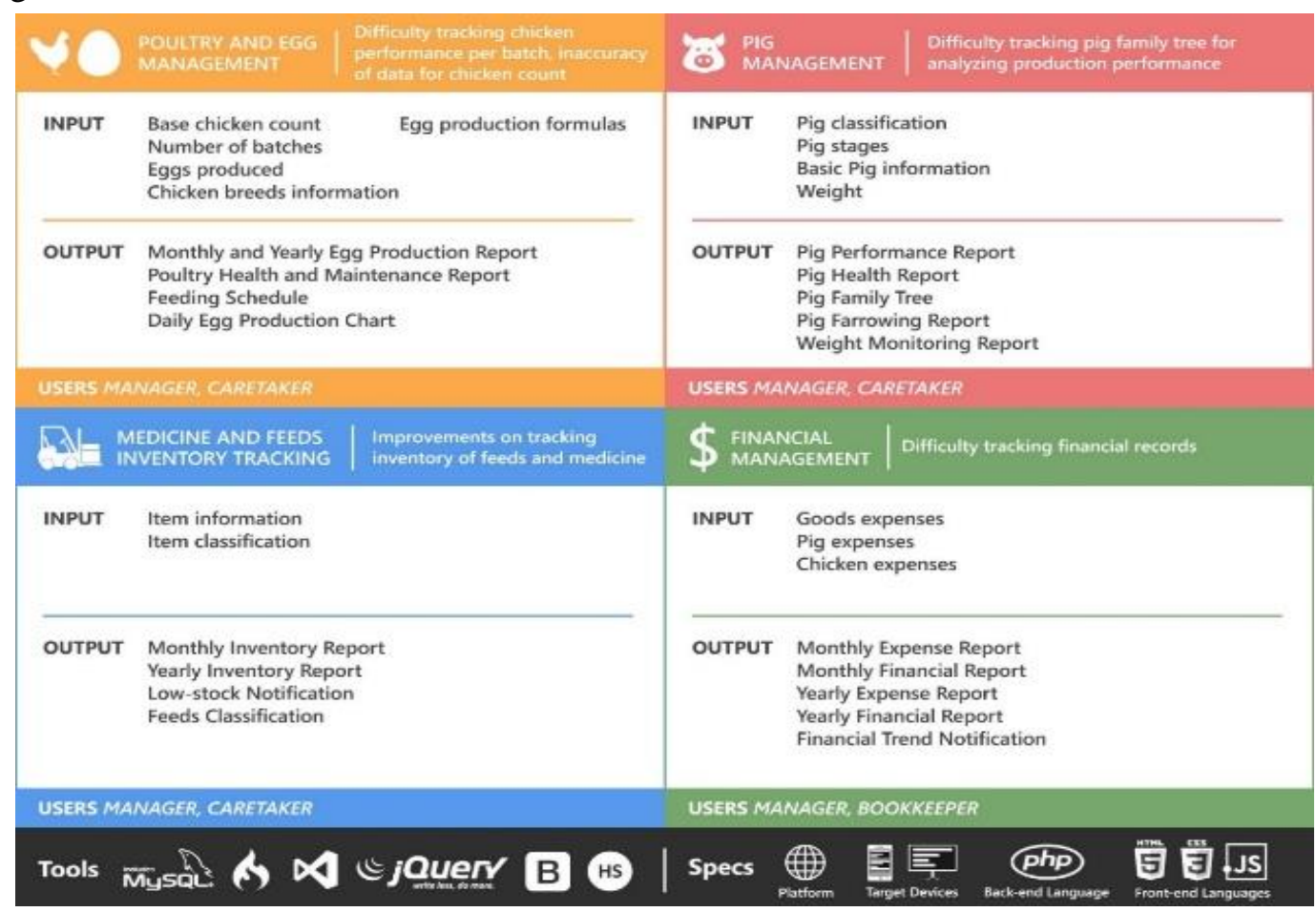

Fig. 1: Conceptual framework of the Decision Support System for the poultry and egg farm.

\subsection{Pig Management}

The Pig Management module has a Weight Monitoring feature that would follow the weight pattern of the pigs if it has reached the required weight in 3 to 4 months. It has a built-in gestation calendar that would predict the farrowing date when the manager or the caretakers input the date the sow has bred. There is also a notification that would inform the caretakers and the manager that the farrowing date is incoming so that they would be able to prepare for the sow's farrowing, such as giving the sow less food for easy farrowing. As an additional feature to improve the breeding of the pigs, the module can track the pig's family tree for analysing production performance. The number of each pig would be stored in the system along with its basic pig information. The child of every pig would be paired to its parents which would be labelled by their number. This information is also listed in each of the pigs which would be listed in the system.

\subsection{Poultry and Egg Management}

The Poultry and Egg Management module can track the breeds of chicken to determine which breed has the best egg production rate. It can also detect the chicken breeds who are not productive, improving the overall production of the eggs. The module also allows the user to generate a summarized Egg Production Report that could be generated every day, month, or year. The generation of the Egg Production Report is a critical for the business to track if the rate of egg production has been met. It also has an Egg Production Trend Notification that would alert whenever discrepancies (such as a sudden drop or increase) arise in the egg production percentage. Additionally, as an improvement in making sure that the farm has an accurate chicken count, an extra feature of the proposed system would be to track the overall chicken count.

\subsection{Feeds and Medicine Inventory Tracking}

The Feeds and Medicine Inventory Tracking module aims to capture, store, and retrieve all the information involving the processes of the farm's inventory management. This module aims to efficiently track the stock of all the feeds and medicines of the animals. The user can add, edit, and restock items on this module. Whenever the farm is stocked low on an item, a notification would pop up signifying them to stock 
up on that item. Additionally, a Inventory Report can be generated by month or year. The report displays the changes made to the stocks based on the date of the report.

\subsection{Financial Management}

The Financial Management module aims to display the overall summary of the finances done by other modules such as the Poultry and Egg Management, Feeds and Medicine Inventory Management, and Pig Management modules. This module aims to provide a clear overview and detailed explanation of the expenses and revenue of the farm to support the decision making of the farm management. In this module, the user can add an expense $\log$ and a revenue log. Additionally, it includes the Expense and Revenue Reports that could be generated by month or year or date range. The module also includes a trend notification to alert the end-user if there is a sudden drop or increase in an expense or revenue.

\section{Conclusions}

Throughout the duration of the project, the researchers have witnessed how DSS can impact the agriculture sector, particularly piggery and poultry farms in the Philippines. This technology can help support farmers make critical decisions to further improve their own processes in their farm for them to maximize their resources and financial capabilities based on the farm's data and other internal or external variables. The DSS for RichDess Poultry and Egg Farm solved the identified company's problem of not being able to maximize their assets (particularly cash) and minimizing their expenses by analysing important data and providing visual representations such as graphs, charts, and reports to help the manager in making the decisions that will benefit the operations of the farm. This is emphasized in the Financial Management Module of the system where the manager can easily visualize the revenue and expenses of the farm. The system helps keep the data organized and automates the necessary computations needed. The researchers also saw the benefits of using a cloud service as an easy means of storing and obtaining data. Utilizing cloud services allows users to access data from anywhere via Internet connection. This allows farm managers to see data from the Farm anytime and anywhere. In cases of computer malfunction or power outage, they could easily retrieve information from the cloud service since the system automatically backups data.

\section{Future Work}

To further enhance the effectiveness of the system, the researchers recommend that the system should be used daily by the farm so that the data will be up to date. This will result to more effective and accurate representations of graphs, charts, and reports which can help in making important decisions for the farm. As an improvement to the system, the researchers suggest that the Pig management module could be improved by monitoring the breeding schedules of boars. Knowing that a boar has not mated in at least three days will increase the probability of the sow becoming pregnant during after the mating process. Furthermore, the researchers encourage farmers, specifically in the poultry, egg, and piggery industry to invest in DSS to make farming more efficient and productive. Using innovative technological solutions such as DSS would help support the economy, improve the quality of the products, gain more income, and provide opportunities for local farmers.

\section{Acknowledgements}

The researchers are grateful for the support of the IT Department, College of Computer Studies of De La Salle University. Special thanks to Professor Michelle Ching, Professor Alain Encarnacion, Professor Geneva Timonera, and Mr. Richard Humarang for guiding the proponents throughout the duration of the project.

\section{References}

[1] F. Lappe, J. Collins, and P. Rosset, "Lessons from the Green Revolution", in World Hunger:12 Myths, 2nd ed. Oakland, CA: Grove Press, 1998.

[2] B. Ahmad, Z. Hussain, and J. Longmire, Farm Management Handbook. Faisalabad, Pakistan: University of Agriculture, 1993. 
[3] R. Forster. Methodology and Practical Development of a System for Planning Management Tasks in Farming Companies. München: Techn. Univ., 2002.

[4] C. Husemann and N. Novkovic, Farm Management Information Systems: A Case Study on a German Multinational Farm, Economics of Agriculture, vol. 61, issue 2, pp. 441-453, 2014.

[5] J. Lindblom, C. Lundstrom, M. Ljung, and A. Jonsson, Promoting sustainable intensification in precision agriculture: review of decision support systems development and strategies. Israel: Precision Agriculture, vol. 18, issue 3, pp. 309-331, 2017.

[6] "Concept and Importance B of Internet: http://www.chm.ph/index.php?option=com_content\&view=article\&id=55\&Itemid=55

[7] M. Cayabyab, “Agriculture: The decline of the poor man's sector," GMA News, May 1, 2013. [Online]. Available GMA News, http://www.gmanetwork.com/news/story/306370/money/agriculture-the-decline-of-thepoor-man-ssector [Accessed February 25, 2017].

[8] C. Valencia, "Boosting agriculture through innovations," The Philippine Star, July 24, 2016. [Online]. Available: The Philippine Star, http://www.philstar.com/agriculture/2016/07/24/1605867/boosting-agriculturethroughinnovations [Accessed February 25, 2017].

[9] K. Agyei-Henaku. "Challenges of the poultry industry in Ghana," Graphic, June 7, 2016. [Online]. Available: Graphic Online, http://www.graphic.com.gh/business/business-news/challenges-of-the-poultry-industryin-ghanaperspective-of-the-medium-small-poultry-farmer-west-of-greater-accraregion.html [Accessed February 25, 2017].

[10] Global Poultry Trends 2014: Rapid Growth in Asia's Egg Output, Sheffield, England: Benchmark House, 2015.

[11] “Top 10 Pork-Producing Countries.” National Pork Board, August 14, 2017. [Online]. Available: Pork Checkoff, http://www.pork.org/pork-quickfacts/home/stats/u-s-pork-exports/top-10-pork-producing-countries/ [Accessed August 20, 2017].

[12] "Philippine beefs up competitiveness of swine industry," The Philippine Star, March 13, 2016.

[13] V. Ocampo. Philippine Statistics Authority, SWINE Industry Performance Report, 2016. [Online]. Available: https://psa.gov.ph/sites/default/files/Swine\%20Industry\%20Performance\%20Report\%2C \%20January\%20\%20June\%202016_0.pdf [Accessed: August 20, 2017].

[14] Philippines. Livestock Research Division and Council for Agriculture, Aquatic and Natural Resources Research and Development - Science and Technology Media Service. Philippine pork to the world. Laguna, Philippines: The Department; 2016. [Online]. Available: http://www.pcaarrd.dost.gov.ph/home/portal/index.php/quickinformationdispatch/2681-philippine-pork-to-the-world [Accessed: August 21, 2017].

[15] S. Ambler and L. Constantine, The Unified Process Transition and Production Phases. Kansas, USA: CMP Books, 2001. 